\title{
Геохимия циркона из верхнепротерозойских отложений няровейской серии Полярного Урала
}

\section{Гракова О.В.}

Институт геологии ФИЦ Коми НЦ УрО РАН, Сыктыьвкар, ovgrakova@geo.komisc.ru

\begin{abstract}
Аннотация. Изучены геохимические особенности цирконов из верхнепротерозойских отложений няровейской серии Полярного Урала. Для цирконов из метабазальтов характерна ровная поверхность и однородное строение зерен. В цирконах углеродсодержащих отложений няровейской серии внутренне строение неоднородное, отмечаются вторичные изменения. Для всех цирконов из верхнепротерозойских отложений, в том числе углеродсодержащих, характерно присутствие $\mathrm{HfO}_{2}, \mathrm{FeO}, \mathrm{Al}_{2} \mathrm{O}_{3}, \mathrm{CaO}$. В метабазальтов минисейшорской свиты присутствует $\mathrm{TiO}_{2}$. В углеродсодержащих отложениях в составе циркона отмечается уран, встречаются уранинит и коффинит.
\end{abstract}

Ключевые слова: метабазальты, углеродсодержащие отложения, циркон, Полярный Урал.

\section{Geochemistry of zircon of Upper Protterozoic deposits of the Nyarovey series of the Polar Ural}

\author{
Grakova O.V. \\ IG FRC Komi SC UB RAS, Syktyvkar, ovgrakova@geo.komisc.ru
}

\begin{abstract}
The geochemical features of zircons from the Upper Proterozoic sediments of the Nyarovey series of the Polar Urals are studied. Zircons from metabasalts are characterized by a flat surface and a uniform grain structure. In the zircons of carbon-bearing sediments of the Nyarovey series, the internal structure is heterogeneous, secondary changes are noted. All zircons from the Upper Proterozoic sediments, including carbonaceous ones, are characterized by the presence of $\mathrm{HfO}_{2}, \mathrm{FeO}, \mathrm{Al}_{2} \mathrm{O}_{3}, \mathrm{CaO}$. In the metabasalts of the Minisheyshor Formation, $\mathrm{TiO}_{2}$ is present. Uranium is noted in carbon-bearing deposits in zircon, and uraninite and coffinite are found.
\end{abstract}

Key words: metabasalts, carbon-containing deposits, zircon, the Polar Urals.

Изучение геохимии циркона верхнепротерозойских отложений представляет большой интеpec, так как он является основным минералом в большинстве метаморфических пород с Zr в качестве структурной составляющей. Он содержит значительную часть следующих элементов-примесей: $\mathrm{U}, \mathrm{Th}, \mathrm{Hf}$ и REE, очень важных при геохимических исследований как индикаторов процессов метаморфизма и для определения возраста (Hoskin, et al., 2003). Цирконы новообразованные или преобразованные из ранее существовавших, в процессе метаморфизма приобретают новые свойства, которые выражаются в изменении морфологии кристаллов, внутреннего строения и геохимического состава (Пыстина, Пыстин, 2018).

Объектом исследования явились верхнепротерозойские отложения (в том числе углеродсодержащие) няровейской серии (рис. 1) Центральноуральской мегазоны Полярного Урала. Верхнехарбейская и минисейшорская свиты, входящие в состав няровейской серии, состоят из кварцитов, филлитовидных, углеродистых, кварц-альбит-слюдистых и кварц-альбит-актинолит-слюдистых сланцев (Душин и др., 2007). Оценка значений РТ-параметров метаморфизма показала, что метаморфиты няровейской серии образовались в условиях эпидот-мусковит-хлоритовой субфации зеленосланцевой фации, в условиях средних и повышенных температур и пониженных давлений (Гракова, 2017).

По химическому составу среди сланцев няровейской серии были выделены орто- и парапороды (Уляшева, 2017). Ортопороды являются метабазальтами, метатуфами и метариолитами. Парапароды представлены метаосадочными породами: метапелитами, метаморфизованными граувакковыми песчаниками и алевролитами, аркозовыми и кварцевыми песчаниками. С металлогенической точки зрения няровейская серия специализирована на благороднометалльное оруденение (Душин и др., 2007). Нами исследованы особенности сульфидной и сульфатной рудной минерализации верхнепро- 


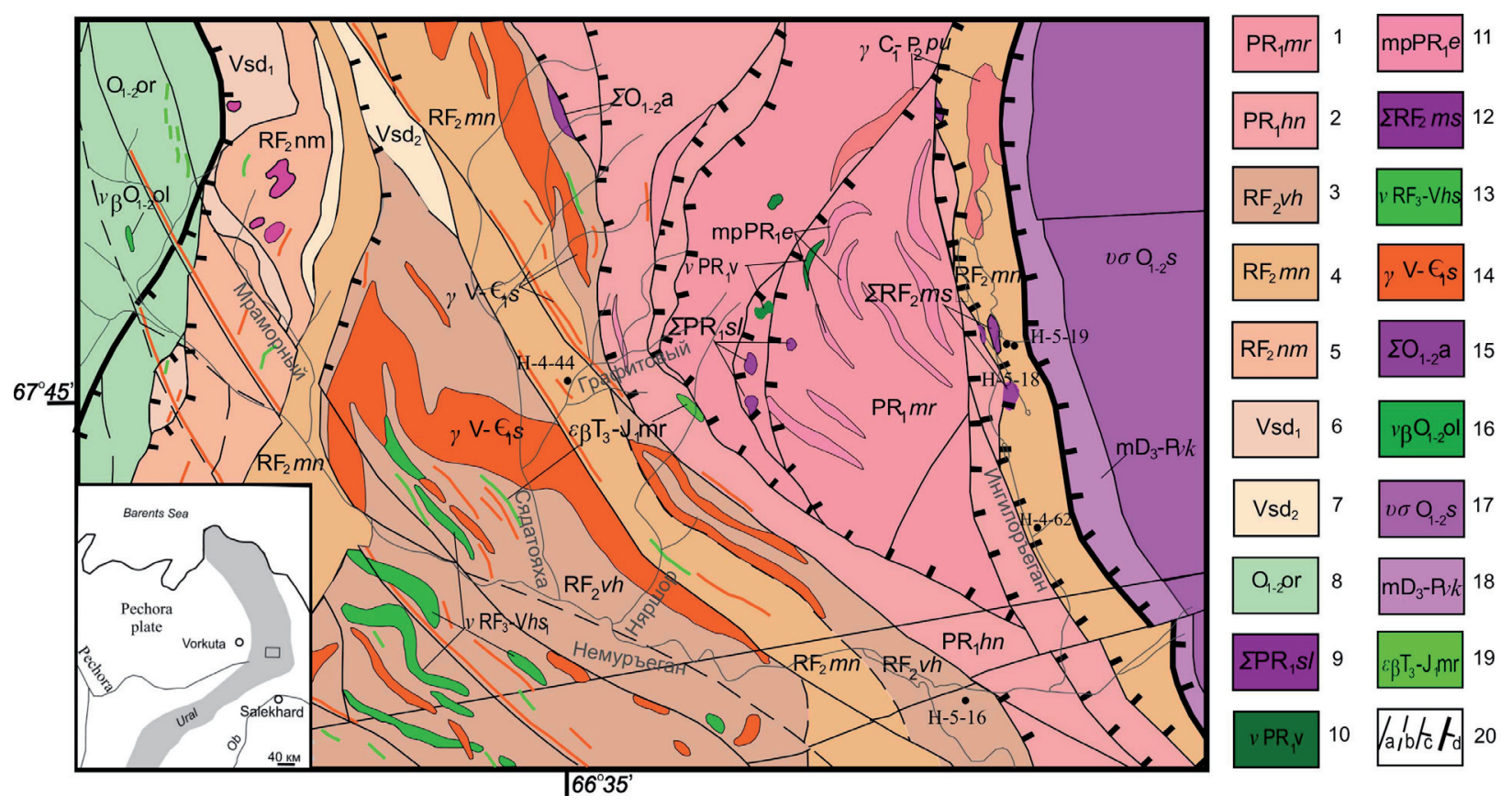

Рис. 1. Схематическая геологическая карта нижнего течения р. Немуръюган (Полярный Урал)

(по Душину и др., 2007).

1 - марункеуская свита; 2 - ханмейхойская свита; 3 - верхнехарбейская свита; 4 - минисейшорская свита;

5 - немуръюганская свита; 6 - нижняя подсвита сядатинская свита; 7 - верхняя подсвита сядатинская свита; 8 - орангская свита; 9 - слюдяногорский комплекс габбро-гипербазитовый эклогитизированный плутонический; 10 - васькеуский комплекс плутонический метагаббро-долеритовый гипабиссальный; 11 - евъюганский комплекс мигматит-плагиогранитовый плутонический; 12 - минисейский комплекс измененных гипербазитов плутонический; 13 - харбей-собский комплекс габбро-гранодиоритовый; 14 - сядатояхинский комплекс гранитовый плутонический; 15 - ампельшорский комплекс измененных ультрамафитов плутонический; 16 - орангюганско-лемвинский комплекс габбро-долеритовый гипабиссальный; 17 - сыумкеуский комплекс дунит-гарцбургитовый плутонический; 18 - войкаро-кемпирсайский комплекс тектонитов; 19 - марунский комплекс щелочно-базитовый; 20 - разрывные нарушения: $\mathrm{a}$ - сдвиги, $\mathrm{b}$ - неустановленной кинематики, с взбросо-надвиги второстепенные, $\mathrm{d}$ - взбросо-надвиги главные. Точками отмечены места и номера отбора проб.

Fig. 1. A schematic geological map of the lower reach of the River Nemuryugan (Polar Urals) (after [5]).

1 - Marunkey series, 2 - Hanmeyhoy series; 3 - Verhneharbey series, 4 - Miniseyshor series; 5 - Slyudyanogorsky complex gabbro-ultramafic plutonic eclogitized; 6 - the lower subordinate is the Sudaden suite; 7 - the upper subordinate is the Sudaden suite; 8 - Orang suite; 9 - Slyudyanogorsk complex gabbro-hyperbasic eclogitized plutonic; 10 - Vaskau complex plutonic metagabbro-dolerite hypabyssal; 11 - Evyugansky complex migmatite plagiogranite plutonic; 7 - Miniseysky complex ultramafic plutonic; 8 - Harbeysobsky complex gabbro-granodiorite; 9 - Syadatoyahinsky complex granite plutonic; 10 - Syumkeusky complex harzburgite-dunite plutonic; 11 - VoikarKempirsay complex tectonites; 12 - the Minisei complex of the modified hyperbasites is plutonic; 13 - Harbey-Sob complex gabbro-granodiorite; 14 - Shadatoyakhinsky granite plutonic complex; 15 - Ampelshory complex of altered ultramafites plutonic; 16 - Orangyugansko-Lamvinsky complex gabbro-doleritic hypabyssal; 17 - Syumke complex of dunite-harzburgite plutonic; 18 - Voykaro-Kempirsay tectonite complex; 19 - Marunsky complex alkaline-basic; 20 - discontinuous violations: $\mathrm{a}$ - shifts, $\mathrm{b}$ - unsettled kinematics, $\mathrm{c}$ - overturn thrusts secondary, $\mathrm{d}$ - upslope thrusts main. Points indicate places and numbers of sampling.

терозойских отложений няровейской серии Полярного Урала. Для метабазальтов няровейской серии характерно присутствие пирита, халькопирита, галенита, барита и англезита (Гракова, 2018).

Было проведено $\mathrm{U}-\mathrm{Pb}$ датирование детритовых цирконов из отложений няровейской серии LA-SF-ICP-MS методом, реализованном на базе одноколлекторного магнитно-секторного массспектрометра с индуктивно связанной плазмой Element XR и установки для лазерной абляции 
UP-213 в ГИН СО РАН. Было показано, что весь разрез няровейской серии, включающий верхнехарбейскую и минисейшорскую свиты, сформировался в позднем рифее (Уляшева и др, 2019).

Химические составы циркона были установлены с помощью сканирующего электронного микроскопа Tescan Vega 3 LMH с энергодисперсионной приставкой Instruments X-Max (аналитики А.С. Шуйский и Е.М. Тропников) в ЦКП «Геонаука» ИГ Коми НЦ УрО РАН.

В метабазальтах вехнехарбейской свиты (рис. 1, точка отбора Н-5-16) циркон составляет короткопризматические от слабоокатанных до окатанных кристаллов размером 5-20 мкм (рис. 2 а-в). Внутреннее строение цирконов однородное, присутствуют разрушенные, возможно, древние, зерна (рис. 2 в). В химическом составе цирконов из метабазальтов содержится $\mathrm{SiO}_{2}$ от 32.63 до 37.92 мас. \%, $\mathrm{ZrO}_{2}$ 65.06-70.45, присутствуют следующие элементы примеси: $\mathrm{HfO}_{2}$ (0.58-2.28 мас. \%), $\mathrm{FeO}$ (0.24-0.57 мас. \%), $\mathrm{Al}_{2} \mathrm{O}_{3}$ (0.49-2.18 мас. \%), $\mathrm{CaO}$ (0.5-1.41 мас. \%) (таблица, номера анализов 1-5).

Цирконы из метабазальтов минисейшорской свиты (рис. 1, точка отбора Н-4-44, H-4-62, Н-5-18, Н-5-19) присутствуют в виде слабо- и хорошоокатанных короткопризматических кристаллов, размером 5-20 мкм (рис. 3. г-3). Структура кристаллов ровная, в некоторых случаях отмечаются трещинки и сколы, внутреннее строение однородное. Содержание $\mathrm{ZrO}_{2}$ составляет от 58.34 до 68.05 мас. \%, $\mathrm{SiO}_{2}$ (32.01-34.88 мас. \%), присутствуют $\mathrm{HfO}_{2}$ (0.59-1.82 мас. \%), $\mathrm{FeO}$ (0.47-1.68 мас. \%), $\mathrm{Al}_{2} \mathrm{O}_{3}\left(0.28-3.92\right.$ мас. \%), $\mathrm{CaO}$ (0.12-2.91 мас. \%), $\mathrm{TiO}_{2}(0.05$ мас. \%) (таблица, номера анализов 6-17).

Изучение геохимии циркона показало отличия во внутреннем строении и химическом составе циркона верхнепротерозойских отложений (в том числе углеродсодержащих) няровейской серии Полярного Урала. Во всех цирконах из верхнепротерозойских отложений няровейской серии, в том числе углеродсодержащих, изученных нами ранее (Гракова, 2018), содержатся следующие элементы: $\mathrm{HfO}_{2}$, отличительной особенностью которого является постепенное накопление относительно циркония в породе, $\mathrm{FeO}, \mathrm{Al}_{2} \mathrm{O}_{3}$ и $\mathrm{CaO}$, им характерно постоянное присутствие в цирконе. В метабазальтах минисейшорской свиты, в отличие от верхнехарбейской, присутствует $\mathrm{TiO}_{2}$, содержание которого может использоваться для определения термометрии насыщения циркона (Денисова, 2016). Для метабазальтов характерна ровная поверхность и однородное строение зерен циркона. В цирконах углеродсодержащих отложений внутренне строение неоднородное, отмечаются вторичные изме-
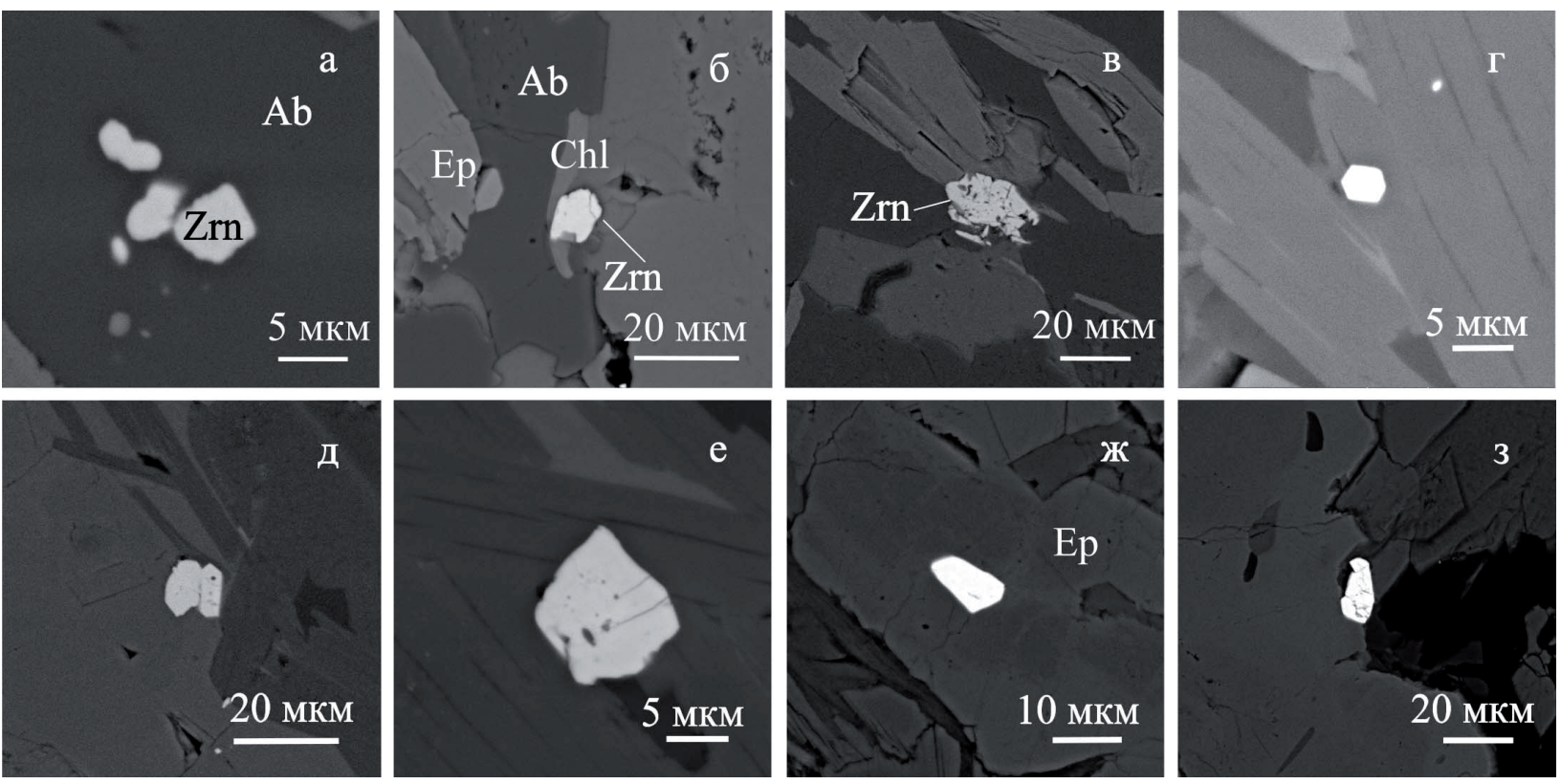

Рис. 2. Цирконы в метабазальтах няровейской серии.

а-в - верхнехарбейской свиты, г-з - минисейшорской свиты, Zrn - циркон, Ab - альбит, Ер - эпидот, Chl - хлорит.

Fig. 2. Zircons in the metasedimentary deposits of the Nyarovey series.

а-в - Verhneharbey series, г-3 - Miniseyshor series, Zrn - zircon, Ab - albite, Ep - epidote, Chl - chlorite. 
нения с «выплавленными», «изъеденными» структурами и трещинами (Гракова, 2018). В углеродсодержащих отложениях в составе циркона отмечается уран, встречаются уранинит и коффинит.

ИсследованияпроведеныврамкахНИРИГКомиНЦУрОРАНГР№АААА-А17-117121270035-0 и при финансовой поддержке Программы фундаментальных исследований РАН № 18-5-5-19.

Химические составы циркона из метабазальтов няровейской серии, мас. \%.

Chemical compositions of zircon from metabasalts of the Nyarovey series, wt. \%.

\begin{tabular}{|c|c|c|c|c|c|c|c|c|}
\hline & $\mathrm{SiO}_{2}$ & $\mathrm{ZrO}_{2}$ & $\mathrm{HfO}_{2}$ & $\mathrm{FeO}$ & $\mathrm{Al}_{2} \mathrm{O}_{3}$ & $\mathrm{CaO}$ & $\mathrm{TiO}_{2}$ & Сумма \\
\hline 1 & 34.71 & 70.45 & 1.4 & - & 0.49 & 0.81 & - & 107.86 \\
\hline 2 & 34.08 & 67.92 & 2.28 & 0.54 & - & - & - & 104.82 \\
\hline 3 & 37.92 & 65.06 & 1.29 & - & 2.18 & - & - & 106.45 \\
\hline 4 & 33.48 & 67.87 & 1.7 & 0.57 & - & 0.5 & - & 104.12 \\
\hline 5 & 32.63 & 65.83 & 0.58 & 0.24 & - & 1.41 & - & 100.69 \\
\hline 6 & 34.03 & 60.07 & 1.82 & 1.68 & 3 & 2.91 & - & 103.51 \\
\hline 7 & 34.88 & 58.34 & 1.79 & 0.87 & 3.92 & - & - & 99.81 \\
\hline 8 & 32.01 & 62.15 & 0.59 & 0.91 & - & 0.23 & - & 95.89 \\
\hline 9 & 32.36 & 65.28 & 0.65 & 0.49 & - & 0.12 & - & 98.9 \\
\hline 10 & 32.22 & 97.03 & 0.87 & 0.85 & - & 0.31 & - & 101.28 \\
\hline 11 & 32.47 & 63.7 & 1.59 & 0.68 & - & 0.31 & - & 98.75 \\
\hline 12 & 33.38 & 66.51 & 1.34 & 0.63 & 0.28 & 0.54 & - & 102.68 \\
\hline 13 & 33.37 & 66.37 & 1.68 & 0.68 & - & 0.33 & - & 102.43 \\
\hline 14 & 32.51 & 67.02 & 0.91 & 0.47 & - & 0.19 & - & 101.1 \\
\hline 15 & 32.61 & 68.05 & 0.96 & - & - & - & - & 101.62 \\
\hline 16 & 32.28 & 67.58 & 1.08 & 0.53 & - & 0.18 & 0.05 & 101.7 \\
\hline 17 & 32.01 & 67.12 & 1.52 & 0.5 & - & - & 0.05 & 101.2 \\
\hline
\end{tabular}

\section{Литература}

1. Гракова О.В. Рудная минерализация няровейской серии (Полярный Урал) // Известия Коми научного центра УрО РАН. № 2 (34). Сыктывкар. 2018. С. 5-11.

2. Гракова О.В. Термодинамические условия метаморфизма верхнепротерозойских отложений Полярного Урала // Вестник Института геологии Коми НЦ УрО РАН. 2017. № 6 (270). С. 13-19.

3. Гракова О.В. Термохимические особенности цирконов верхнепротерозойских отложений няровейской серии и немуръюганской свиты (Полярный Урал) // Вестник Института геологии Коми НЦ УрО РАН. 2018. № 11 (287). С. 13-19.

4. Денисова Ю.В. Термометрия циркона из гранитоидов Приполярного Урала // Вестник Института геологии Коми НЦ УрО РАН, Сыктывкар. 2016. № 12. С. 37-44.

5. Душин В.А., Сердюкова О.П., Малюгин А.А. Государственная геологическая карта Российской Федерации масштаба 1:200000. Издание второе. Серия Полярно-Уральская. Листы Q-42-I, II. Объяснительная записка. СПб.: ВСЕГЕИ. 2007. 340 с.

6. Пыстина Ю.И., Пыстин А.М. Распределение U и Тh в цирконах метаморфических пород и гранитоидов Севера Урала // Сборник статей XII Межрегиональной научно-практической конференции «Геология, полезные ископаемые и проблемы геоэкологии Башкортостана, Урала и сопредельных территорий». Уфа. 2018. С. 294-299.

7. Уляшева Н.С. Геохимические особенности и геодинамическая обстановка формирования верхнепротерозойских отложений няровейской серии // Вестник Института геологии Коми НЦ УрО РАН. 2017. № 5 (269). C. 20-30.

8. Уляшева Н.С., Пыстин А.М., Пыстина Ю.И., Гракова О.В., Хубанов В.Б. Первые результаты U-РВ LA-SF-ICP-MS-датирования детритовых цирконов из среднерифейских (?) терригенных отложений Полярного Урала // ДАН. 2019. Т. 485. № 4. С. 488-492. DOI: https://doi.org/10.31857/S0869-56524854488-492.

9. Hoskin P.W.O., Schaltegger Urs. The Composition of Zircon and Igneous and Metamorphic Petrogenesis. Reviews in Mineralogy and Geochemistry. 2003. V. 53. No. 1. P. 27-62. DOI : 10.2113/0530027. 